\title{
32 The Burden of Communicable and Non-Communicable Diseases in Developing Countries
}

\author{
A. Boutayeb
}

1 Introduction

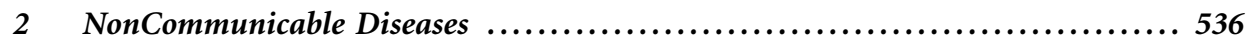

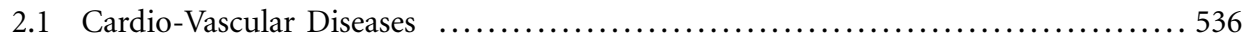

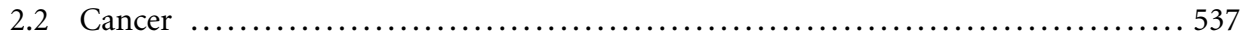

2.3 Chronic Respiratory Diseases ....................................... 537

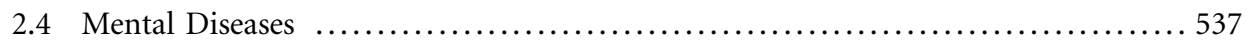

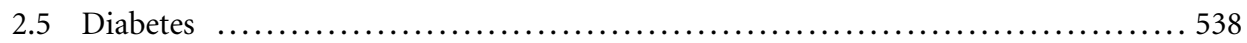

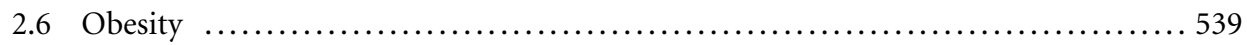

3 Communicable Diseases ............................................ 539

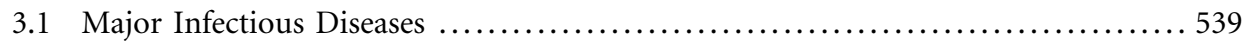

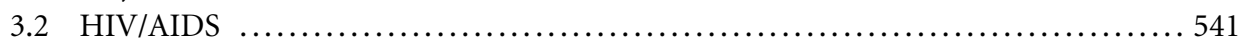

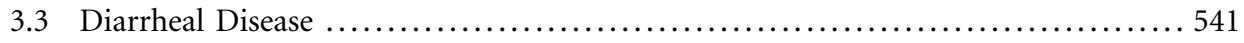

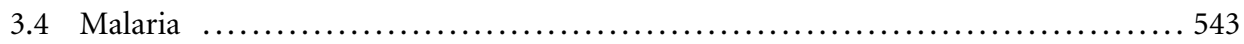

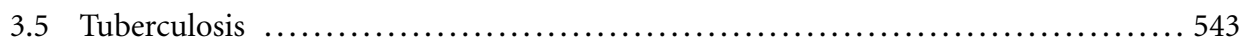

3.6 Preventable Sexually Transmitted Diseases .............................. 544

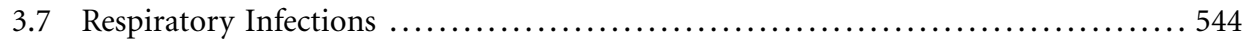

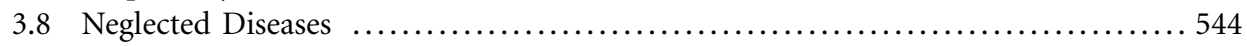

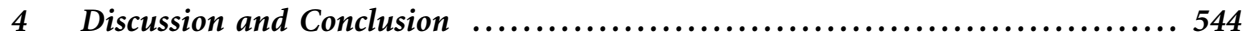

Summary Points ............................................... 545 
Abstract: Worldwide, developed and developing countries are facing the double burden of communicable and $\boldsymbol{\nabla}$ noncommunicable diseases. However, developing countries are more exposed and more vulnerable due to a multitude of factors, including geographic, demographic and socio-economic factors. Noncommunicable diseases like cardio-vascular diseases, cancer, diabetes, chronic obstructive pulmonary disease and mental disorders are affecting developing countries with an increasing trend. In parallel, $\boldsymbol{\nabla}$ communicable diseases such as HIV/AIDS, malaria, tuberculosis, acute respiratory infections and diarrheal disease are causing high mortality rates especially in low and middle income countries. Other diseases like the so-called neglected diseases are exclusively afflicting developing countries. Low-income countries are particularly affected by lymphatic filariasis, leishmaniasis, schistosomiasis, Buruli ulcer, cholera, cysticercosis, dracunculiasis, foodborne trematode infections, hydatidosis, soil-transmitted helminthiasis (ascariasis, trichuriasis, hookworm diseases), trachoma, sleeping sickness, onchocerciasis, Chagas disease, dengue and others. Beyond the high mortality and morbidity rates caused by communicable and/or noncommunicable diseases in developing countries, the global burden includes economic losses due to care for diseases and disabilities but also as a lack of productivity. More generally, communicable and noncommunicable diseases are impeding human development in developing countries by their negative impact on education, income and life expectancy and other health indicators. In sub-Saharan African countries, devastating consequences are already strikingly apparent in terms of life expectancy and $\boldsymbol{O}$ human development index (HDI) in general.

A large part of the burden caused by noncommunicable diseases like cardio vascular diseases, cancer, diabetes, obesity and others can be avoided by preventive measures, early diagnosis and detection and mainly by controlling risk factors such as smoking, alcohol, diet, and physical inactivity. Similarly, the impact of communicable diseases can be alleviated by efficient strategies, including affordability of treatments, development of new vaccines and medicines, improvement of environmental conditions and general incentives and sensitization.

List of Abbreviations: AIDS, acquired immune defense system; $B M I, \odot$ body mass index; $C D$, communicable disease; $C O P D$, chronic obstructive pulmonary disease; $C V D$, cardio vascular disease; DALY, disability adjusted life years; DOTS, $\boldsymbol{\otimes}$ directly observed therapy strategy; HDI, human development index; $H I V$, human immunodeficiency virus; $N C D$, noncommunicable disease; $N D$, neglected disease; $S A R S$, severe acute respiratory syndrome; $S T D$, sexually transmitted disease; UNAIDS, United Nations AIDS; UNESCO, United Nations Educational, Scientific and Cultural Organization; UNICEF, United Nations Children's Fund; WHO, World Health Organization; $Y L D$, years lived with disability; $Y L L$, years of life lost

\section{Introduction}

By the dawn of the third millennium, the developing world's population is facing the double burden of communicable and noncommunicable diseases. Although at different stages and degrees, developed and developing countries alike, are struggling against the alarming trends of diseases such as cardiovascular diseases (CVDs), diabetes, cancer, chronic respiratory diseases, mental conditions, HIV/AIDS, malaria, tuberculosis and a multitude of other known existing, emerging or re-emerging diseases like measles, hepatitis, cholera, meningitis, Ebola, SARS and others ( $\bullet$ Figure 32-1). 


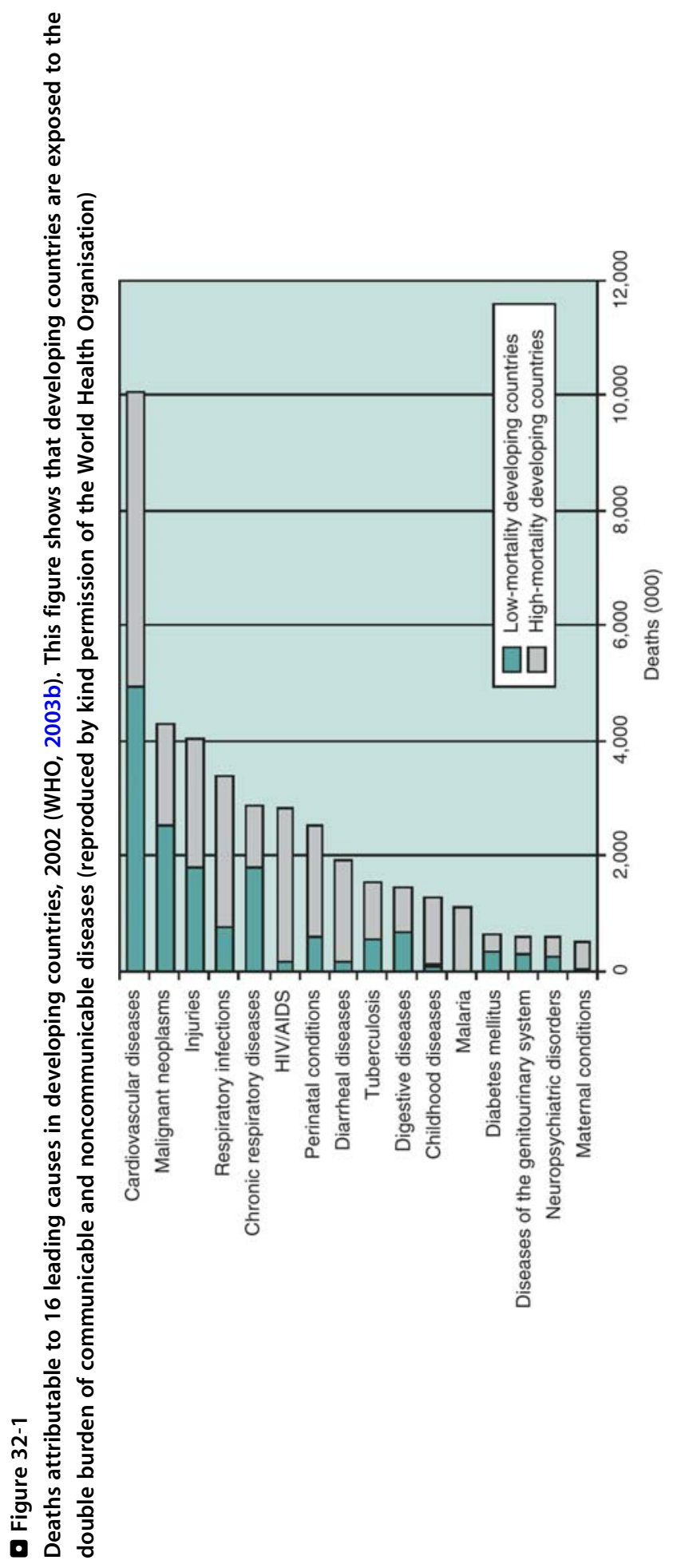


According to the World Health Organization report (WHO, 2002), it has been estimated that, in 2001, approximately $60 \%$ of the 56.5 million total reported deaths in the world and approximately $46 \%$ of the global burden of disease is attributable to chronic diseases and cardiovascular disease in particular. Deaths caused by noncommunicable diseases dominate the mortality statistics in five out of six regions of the World Health Organization. The exception is Africa where deaths caused by HIV/AIDS, malaria, tuberculosis and other communicable diseases are predominant (\$ Table 32-1).

In 2007, nearly 60 million deaths occurred worldwide with the large part in developing countries. Three-quarters of adult deaths are due to noncommunicable diseases, with coronary heart disease causing 7.6, stroke responsible for 5.7 million deaths, and hypertensive and other heart conditions causing an additional 4 million deaths. In the meantime, infectious diseases continue to cause millions of deaths and disabilities especially in Africa (see the Chapter The impact of infectious disease in Africa in this book). Acute respiratory infections, HIV/AIDS, diarrhea, malaria and tuberculosis are the biggest infectious killers in the world and particularly in Africa. These five diseases are causing some 13 million deaths per year, but besides mortality figures, they also engender a high burden in terms of $\boldsymbol{\nabla}$ disability and morbidity, affecting individuals, families and entire societies. A multitude of other diseases, including the so-called neglected diseases like lymphatic filariasis, leishmaniasis, schistosomiasis, Buruli ulcer, cholera, cysticercosis, dracunculiasis, foodborne trematode infections, hydatidosis, soil-transmitted helminthiasis (ascariasis, trichuriasis, hookworm diseases), trachoma, trypanosomiasis, onchocerciasis, Chagas disease, dengue and others are affecting low and middle income countries in exclusivity (WHO, 2003a) (See the Chapter The burden of neglected diseases in developing countries in this book).

Beyond mortality statistics, different methods can be considered to quantify the burden of disease expressed in terms of socio-economic costs such as productivity losses, care

\section{- Table 32-1}

Deaths by causes in WHO regions, estimates for 2002 (WHO, 2003b)

\begin{tabular}{|l|c|c|c|}
\hline Cause WHO regions & $\begin{array}{c}\text { Communicable } \\
\text { maternal and perinatal } \\
\text { conditions and } \\
\text { nutritional deficiencies }\end{array}$ & $\begin{array}{c}\text { Noncommunicable } \\
\text { diseases }\end{array}$ & Injuries \\
\hline Africa & 7,779 & 2,252 & 747 \\
\hline The Americas & 875 & 4,543 & 540 \\
\hline Eastern Mediterranean & 1,746 & 2,030 & 391 \\
\hline Europe & 567 & 8,112 & 803 \\
\hline South-East Asia & 5,730 & 7,423 & 1,467 \\
\hline Western Pacific & 1,701 & 9,000 & 1,231 \\
\hline World & 18,416 & 33,424 & 5,188 \\
\hline $\begin{array}{l}\text { Percentage of total } \\
\text { deaths }\end{array}$ & $32.3 \%$ & $58.6 \%$ & $9.1 \%$ \\
\hline
\end{tabular}

This table shows that three out of four deaths caused by communicable diseases occurred in Africa and South-East Asia. Developing countries are seriously affected by the double burden of communicable and noncommunicable diseases (reproduced by kind permission of the World Health Organisation) 
and treatment, hospitalization and handicap. In order to overcome the specific problems of each country, the most used method during the last decade is the approach that measures the global burden of disease in terms of Disability Adjusted Life Years (DALYs) which is a combination of Years of Life Lost (YLL) through premature death, and Years Lived with Disability (YLD). Thus, DALY is thought of as one lost year of healthy life (WHO, 2003b) (> Table 32-2).

In Low-income and middle-income countries, diseases are generally affecting people at a younger age compared to their counterparts in the developed world. Consequently, the double burden of communicable and noncommunicable diseases constitutes a major impediment to economic and human development in developing countries ( $>$ Figure 32-2).

Different studies have been devoted to the disease impact on economic and human development. Curiously and fortunately, all the studies conclude that a large part of the disease burden can be avoided by preventive and curative strategies. According to a series of studies published recently by the Lancet, $80 \%$ of the 35 million deaths caused by cardiovascular diseases, cancer, chronic respiratory diseases, diabetes and other noncommunicable diseases in 2005, occurred in low-income and middle-income countries. Achievement of the global goal of reducing chronic disease death rates by $2 \%$ every year would save billions of dollars and avert 36 million deaths between 2005 and 2015 mainly in developing countries (Abegunde et al., 2007). A report of the World Bank, concentrating on the economic benefit of tuberculosis control in the 22 countries with the highest burden of TB, has shown that, moving from no DOTS to sustained DOTS in a global plan strategy between 2006 and 2015, will yield a benefit of US\$ 129 billion quasi-totally in developing countries (Laxminarayan et al., 2007). Similarly, the impact of HIV/AIDS and other diseases on economic and human development was considered by several authors (Boutayeb, 2006; Dzenovska et al., 2005; UNAIDS, 2006).

- Table 32-2

Burden of diseases in DALYs by cause in WHO $(2002,2003 \mathrm{~b})$

\begin{tabular}{|l|c|c|c|}
\hline Cause WHO region & $\begin{array}{c}\text { Communicable diseases, } \\
\text { maternal and perinatal } \\
\text { conditions and nutritional } \\
\text { deficiencies (in thousands) }\end{array}$ & $\begin{array}{c}\text { Noncommunicable } \\
\text { diseases (in thousands) }\end{array}$ & $\begin{array}{c}\text { Injuries (in } \\
\text { thousands) }\end{array}$ \\
\hline Africa & 268,240 & 64,851 & 31,008 \\
\hline The Americas & 26,677 & 99,080 & 19,863 \\
\hline $\begin{array}{l}\text { Eastern } \\
\text { Mediterranean }\end{array}$ & 64,817 & 57,233 & 17,477 \\
\hline Europe & 14,170 & 114,289 & 21,315 \\
\hline South-East Asia & 183,563 & 186,376 & 55,547 \\
\hline Western Pacific & 54,129 & 173,466 & 37,003 \\
\hline Total & 612,194 & 696,632 & 182,591 \\
\hline $\begin{array}{l}\text { Percentage of total } \\
\text { deaths }\end{array}$ & $41.1 \%$ & $46.7 \%$ & $12.2 \%$ \\
\hline
\end{tabular}

Whereas the burden of noncommunicable diseases is shared between developed and developing countries, the quasi-totality of the burden of communicable diseases is afflicting developing countries (reproduced by kind permission of the World Health Organisation) 


\section{- Figure 32-2}

Disease burden (DALYs) among adults (aged 15 years and over) By broad cause, selected epidemiological subregions, 2002 (WHO, 2003b). Deaths caused by noncommunicable diseases dominate the mortality statistics in five out of six regions of the World Health Organization. The exception is Africa where deaths caused by communicable diseases are predominant (reproduced by kind permission of the World Health Organisation)

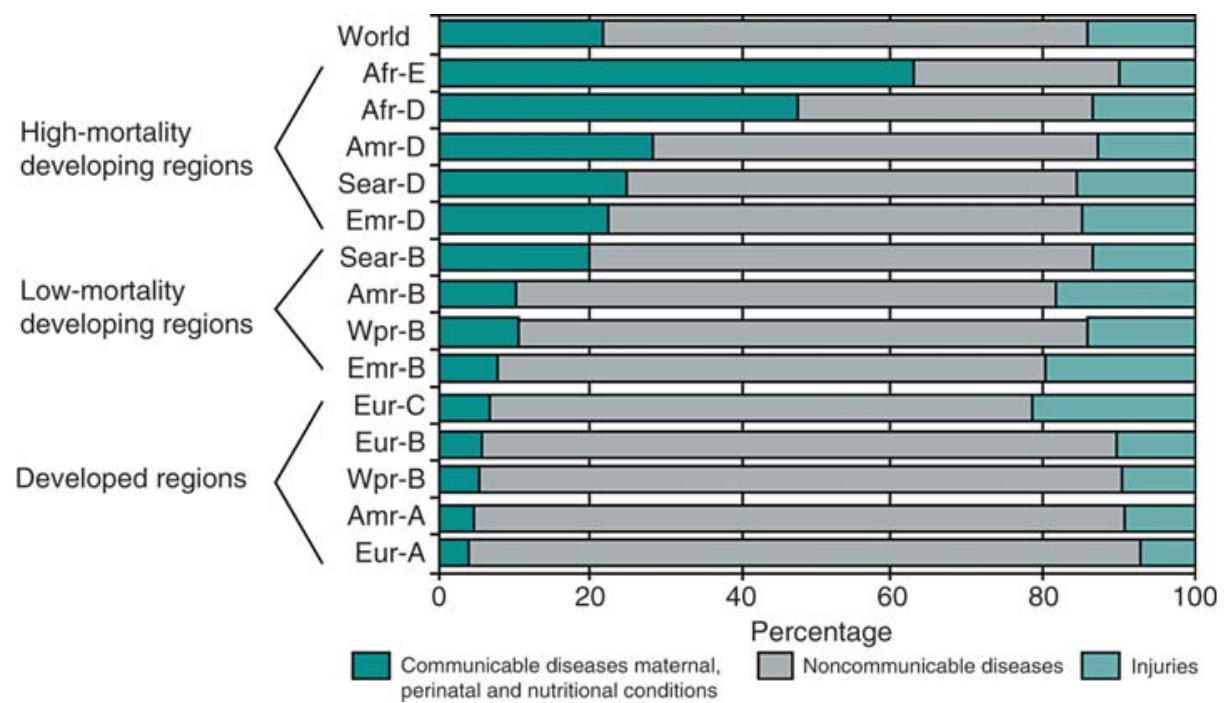

\section{$2 \quad$ NonCommunicable Diseases}

\subsection{Cardio-Vascular Diseases}

Cardio-Vascular Disease is the name for the group of disorders of the heart and blood vessels and includes: hypertension (high blood pressure), coronary heart disease (heart attack), cerebrovascular disease (stroke), peripheral vascular disease, heart failure, rheumatic heart disease, congenital heart disease and cardiomyopathies. An estimated 17.5 million deaths were caused by these diseases in 2005, representing 30\% of all deaths occurring in the world. Ischemic heart disease and cerebrovascular disease together, caused more than 13 million deaths, whereas hypertensive and other heart conditions were responsible for an additional 4 million deaths. If the present trend is not reversed or at least stopped, some 20 million people will die from CVDs by 2015. Once associated with rich and industrialized nations, CVDs are now seriously affecting developing countries. Nearly $80 \%$ of CVD deaths occur in developing countries where they are expected to be the leading cause of death by 2010. In some countries of the East Mediterranean Region 40\% of all deaths are caused by CVDs (Alwan, 1997; Boutayeb and Boutayeb, 2005; Tazi et al., 2003). Among the 20 "lucky" million people who survive annually heart attacks and stroke, a number of "unlucky" survivals are living in developing countries where they cannot afford the continuing costly treatment and clinical care. Beyond mortality figures, CVDs are also imposing a huge disease burden. More than $85 \%$ of the global CVD burden happens in developing countries. In general, theses diseases strike people in their mid-life years, affecting their productivity, undermining the family budget 
and impeding the economic and human development of the whole society. Moreover, studies have shown that lower socio-economic groups have greater $\$$ prevalence of risk factors, higher

( incidence and higher mortality (Reddy, 2002; Yusuf et al., 2001).

\subsection{Cancer}

Cancer is a major cause of mortality and morbidity worldwide but its trend is more pronounced in developing countries and especially in those with middle-income economies.

Over $50 \%$ of the 10 million new cases and $56 \%$ of the 7 million deaths caused by cancer in 2000 , occurred in developing countries. The future is more alarming since it is predicted that, between 2000 and 2020, the number of cases will increase by $73 \%$ in developing countries compared to a $29 \%$ increase in developed countries. While the incidence and prevalence of some sites of cancer such as breast and cervical cancer have regressed in developed countries, they still have devastating consequences in developing countries mainly due to late detection. Other types such as lung cancer are exponentially exploding as a consequence of increase in the use of tobacco and alcohol. Finally, many types of cancer such as colorectal, stomach and liver cancer are "flourishing" in developing countries due to the multidimensional transition, in which most developing countries are completely or partially engaged, and its corollaries on inadequate diet and physical inactivity (Boutayeb and Boutayeb, 2005).

\subsection{Chronic Respiratory Diseases}

Chronic respiratory diseases constitute a major burden for health systems in developing countries suffering from lack of standards protocols for assessing and managing respiratory diseases such as asthma and chronic obstructive pulmonary disease (COPD) (Ait-Khaled et al., 2001). According to the World Health Organisation, chronic obstructive pulmonary disease causes 2.5 million deaths and some 25 million DALYs every year. Despite its chronic nature affecting some 600 million people, and the fact that it is the fifth and sixth leading cause of death in high and low- income countries respectively, COPD is thought to be overlooked, under-diagnosed, under-treated and under-funded, and also neglected by the public, pharmaceutical industry and physician alike when compared to other major killers such as cardiovascular disease and stroke (The Lancet, 2007). If urgent and efficient actions are not taken, COPD will be the third leading cause of death by 2020. This exponentially growing trend is partly explained by the ageing of the world's population and the sustained use of tobacco, which is the most important risk factor for this disease (Buist et al., 2007). Different authors have attempted to quantify its incidence, prevalence and global burden.

\subsection{Mental Diseases}

Mental illnesses are affecting all countries with an increasing trend. Worldwide, it is estimated that 450 million people suffer from mental, neurological or behavioral problems. About 120 million people currently live with depression and some 900,000 people commit suicide each year. In 2000, depression was the fourth leading cause of disease burden (Moussavi et al., 2007). 
Schizophrenia affects 24 million people and nearly 40 million people live with dementia. In particular, with ageing populations, the prevalence of Alzheimer's disease is rising rapidly. More than $80 \%$ of the 50 million affected by epilepsy live in developing countries. It is thought that at least $70 \%$ of people affected can be seizure-free if treated with antiepileptic drugs. However, the vast majority remain untreated (in Africa, $80 \%$ receive no treatment). More generally, cost-effective treatments can be made available for most disorders but at least twothirds of people who are mentally ill receive no treatment (Thornicroft, 2007). The reader can find more details in the series of articles devoted by Lancet in its volume 370 to mental disorders under the title "why do we invest so little in our mental health care?". Mental illnesses are affecting developed and developing countries alike. However, due to lack of budget and human resources, the impact is more pronounced in low and middle-income countries where neglected mental illnesses are causing important economic costs and impeding human development. It should be stressed that, in developing countries, children and adolescents are particularly affected by mental or behavioral problems due to injuries, childhood infections and lack of oxygen at birth.

\subsection{Diabetes}

Worldwide, in 20 years, diabetes has had a sixfold increase, jumping from 30 million in 1985 to around 180 million in 2005. If the trend is maintained, the figure is expected to reach 370 million in 2030.

Diabetes is no more a disease of the "rich". It is now sweeping the whole globe with a particular increase in developing countries. By 2025, $80 \%$ of all new cases of diabetes will take place in low and middle income countries (Boutayeb et al., 2004). Moreover, diabetes affects people of developing countries at a younger age compared with their counterpart in developed countries. Although the disease impact is comparable to that of HIV/AIDS, it remains underevaluated, continuing silently to cause a high burden.

In developing countries, more than $50 \%$ of people living with diabetes ignore that they have the disease. Consequently, most of them will rapidly end up with irreversible complications and morbidity.

In 2007, about 3.5 million deaths were caused by diabetes as a consequence of increasing incidence and prevalence which are now reaching alarming thresholds. Worldwide, every year some 6 million join the group of diabetics, whereas, in many countries in Asia, the Middle East, Oceania and the Caribbean, the prevalence reaches $12-20 \%$ of the adult population.

Although type 2 diabetes is the most frequent, representing $90-95 \%$ of the global number of diabetics, $\boldsymbol{\nabla}$ insulin-dependent diabetes is particularly attracting attention in some African countries where lack of $\boldsymbol{\nabla}$ insulin is causing premature deaths.

Beyond, high rates of mortality, diabetes is responsible for an excessive burden due essentially to micro- and macro-vascular complications such as blindness, kidney failure, amputations and heart diseases. As a chronic disease, diabetes is asking a large toll at all levels. It is estimated that the disease causes annually more than one million amputations, about $5 \%$ of blindness due to diabetic retinal disease and a large number of renal failures. Economically, about 300 billion US\$ (215-375) were spent worldwide in care for diabetes and its complications in 2007. In developing countries where four out of five people pay for their own treatments and medicines, as much as $25 \%$ of family income may be devoted to diabetes care (WHO, 2007). 


\subsection{Obesity}

According to the World Health Organisation, obesity is defined as "a condition of abnormal or excessive fat accumulation in adipose tissue, to the extent that health may be impaired." A convenient measurement of obesity is given by the Body Mass Index (BMI) which is a simple weight to (square) height ratio $\left(\mathrm{kg} / \mathrm{m}^{2}\right)$. Worldwide, obesity and overweight affect 1.2 billion people of which 300 million are clinically obese. In some developed countries, the prevalence of overweight and obesity reaches $60 \%$ (Drewnowski and Specter, 2004). However, obesity is no more a feature of rich countries alone. It is affecting more and more seriously developing countries. A special interest should be paid to the growing prevalence of obesity in children and the concern about the co-existence of under- and overweight people in developing countries in general and in African countries in particular.

Obesity and overweight lead to adverse metabolic changes such as insulin resistance, increasing blood pressure and cholesterol. Considered as a disease, obesity diminishes both quality of life and life expectancy, but it is also a common risk factor for other diseases like CVDs, diabetes, arthritis and many types of cancer. Besides genetic, gender and socioeconomic factors, the alarmingly increasing trend of obesity is principally linked to the many transition forms (demographic, epidemiological ( $($ epidemiology), geographic, democratic and economic). In particular, the transition from a rural to an urban lifestyle and its corollary of nutrition transition characterized by a higher energy density diet with a greater role for fat and added sugar in foods, greater saturated fat intake mostly from animal sources, reduced intakes of fiber, fruit and vegetables (WHO, 2003c).

\section{Communicable Diseases}

\subsection{Major Infectious Diseases}

With malnutrition as a common contributor, the five biggest infectious killers in the world are acute respiratory infections, HIV/AIDS, diarrhea, malaria and tuberculosis, responsible for nearly $80 \%$ of the total infectious disease burden and claiming about 12 million people per year mainly in developing countries (> Table 32-3 and $(32-4)$.

\section{- Table 32-3}

Estimates of the COPD burden worldwide

\begin{tabular}{|l|l|l|}
\hline Author & \multicolumn{1}{|c|}{ Age category } & \multicolumn{1}{|c|}{ Prevalence } \\
\hline Ezzati and Lopez (2000) & 40 years or older & $(9-10 \%)$ \\
\hline Lopez et al. (2007) & 30 years or older & Men (0.6-4\%) Women $(0.2-3.2 \%)$ \\
\hline Buist et al. (2007) (BOLD study) & 40 years or older & Men $11.8 \%$, Women $8.5 \%$ \\
\hline Menezes et al. (2005) (PLATINO study) & 60 years or older & $18.4-32.1 \%$ \\
\hline Yin et al. (2007) & 40 years or older & $7.2 \%$ \\
\hline
\end{tabular}

Several authors have tried to estimate the prevalence of COPD in different age categories. The various estimates produced are another indication proving that this disease needs more attention. BOLD burden of lung disease; PLATINO Latin-American project for investigation of pulmonary obstruction 
- Table 32-4

Main causes of Mortality due to infectious diseases, 2001 (WHO, 2003b)

\begin{tabular}{|l|c|c|}
\hline Disease & $\begin{array}{c}\text { Deaths per year } \\
\text { (Worldwide, in million) }\end{array}$ & $\begin{array}{c}\text { Deaths per year } \\
\text { (developing countries, in million) }^{\text {a }}\end{array}$ \\
\hline Respiratory infections & 3.9 & $3.2(82 \%)$ \\
\hline AIDS & 3.0 & $2.7(90 \%)$ \\
\hline Diarrheal diseases & 1.9 & $1.8(95 \%)$ \\
\hline Tuberculosis & 1.6 & $1.5(95 \%)$ \\
\hline Malaria & 1.1 & $1.08(98 \%)$ \\
\hline
\end{tabular}

${ }^{\text {a }}$ Author's estimation

The five biggest infectious killers in the world and in Africa are acute respiratory infections, HIV/AIDS, diarrhea, malaria and tuberculosis. These diseases contribute not only to high mortality rate, they also engender a high burden in terms of disability and morbidity (reproduced by kind permission of the World Health Organisation)

- Table 32-5

Leading causes of deaths in children in developing countries, 2002 (WHO, 2003b)

\begin{tabular}{|l|c|c|}
\hline Condition & Numbers (in thousands) & Percentage of all deaths (\%) \\
\hline Perinatal conditions & 2,375 & 23.1 \\
\hline Lower respiratory infections & 1,856 & 18.1 \\
\hline Diarrheal diseases & 1,566 & 15.2 \\
\hline Malaria & 1,098 & 10.7 \\
\hline Measles & 551 & 05.4 \\
\hline Congenital anomalies & 386 & 03.8 \\
\hline HIV/AIDS & 370 & 03.6 \\
\hline Pertussis & 301 & 02.9 \\
\hline Tetanus & 185 & 01.8 \\
\hline Protein-energy malnutrition & 138 & 01.3 \\
\hline Other causes & 1,437 & 14.0 \\
\hline Total & 10,263 & 100 \\
\hline
\end{tabular}

Lower respiratory infections, malaria, diarrhea, measles, AIDS and other infectious diseases are the leading causes of child mortality in developing countries. Almost all child deaths occur in developing countries and about half of them especially in Africa (reproduced by kind permission of the World Heath Organisation)

Despite the success of vaccination programs for polio and many childhood diseases, malaria, tuberculosis, HIV/AIDS and others are still out of control in the majority of African countries. Children remain at high risk. Indeed, in 2002, of the 57 million deaths reported worldwide, 10.5 million deaths were among children of less than 5 years of age, of which $98 \%$ were in developing countries in general and in Africa in particular (WHO, 2003a, 2003b, 2004) ( $($ Table 32-5). Consequently, while life expectancy at birth reached 78 years for women in developed countries, it fell back to less than 46 years in sub-Saharan Africa ( $($ Figure 32-3). 


\section{- Figure 32-3}

Child mortality in the six WHO regions, 2002 (WHO, 2003b). This figure shows clearly the gap existing between developed and developing countries in child mortality. Almost all child deaths are occurring in developing countries with about $50 \%$ of deaths taking place in Africa (reproduced by kind permission of the World Heath Organisation)

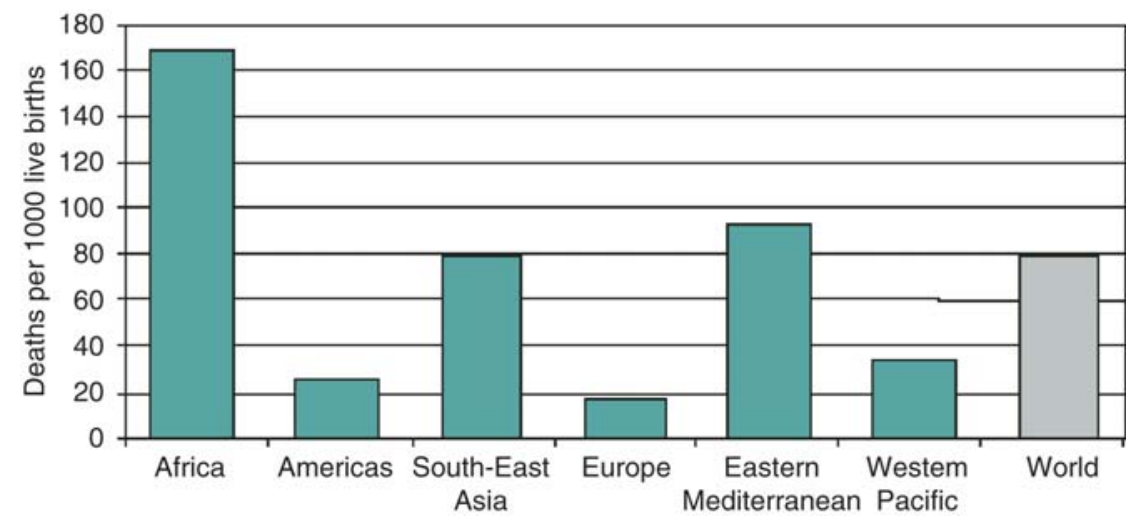

\section{$3.2 \quad$ HIV/AIDS}

HIV/AIDS is an infectious disease that emerged a quarter of century ago, causing so far about 40 million deaths and leaving millions of orphan children and disabled adults. If the present trend is maintained, by 2020 AIDS will have caused more deaths than any other disease ( epidemics in history. Beyond the fact that the disease is now recognized as a major health emergency, it has also imposed its burden on the whole development of societies. In the most affected countries of Africa, devastating consequences are already strikingly apparent not only on health systems and health indicators but also in terms of income and productivity, education and knowledge, human rights and gender equality (UNAIDS, 2006). It is know commonly admitted that HIV/AIDS is impeding the development of many countries, especially in sub Saharan Africa were lived $80 \%$ of the 3 million people killed by HIV/AIDS in 2002. Many countries have a $20 \%$ or more prevalence of HIV. Consequently, life expectancy is decreasing and the future is more alarming if nothing is done to reverse or at least to stop the present trend of HIV/AIDS (『 Figure 32-4) (Dzenovska et al., 2004).

\subsection{Diarrheal Disease}

It is well known that diarrheal disease is among the leading causes of mortality and morbidity in children and that the quasi-totality of deaths caused by diarrhea occurs in developing countries. Using different methods and sources of information, several authors have attempted to evaluate the burden of this disease. Despite the differences existing between estimates, they all show a declining trend in mortality figures but a relatively stable morbidity (Bern et al., 1992; Kosek et al., 2003; Murray et al., 2001; NVD, 1986; Rohde and Northrup, 1976; Snyder and Merson, 1982; WHO, 2003a) († Table 32-6). 


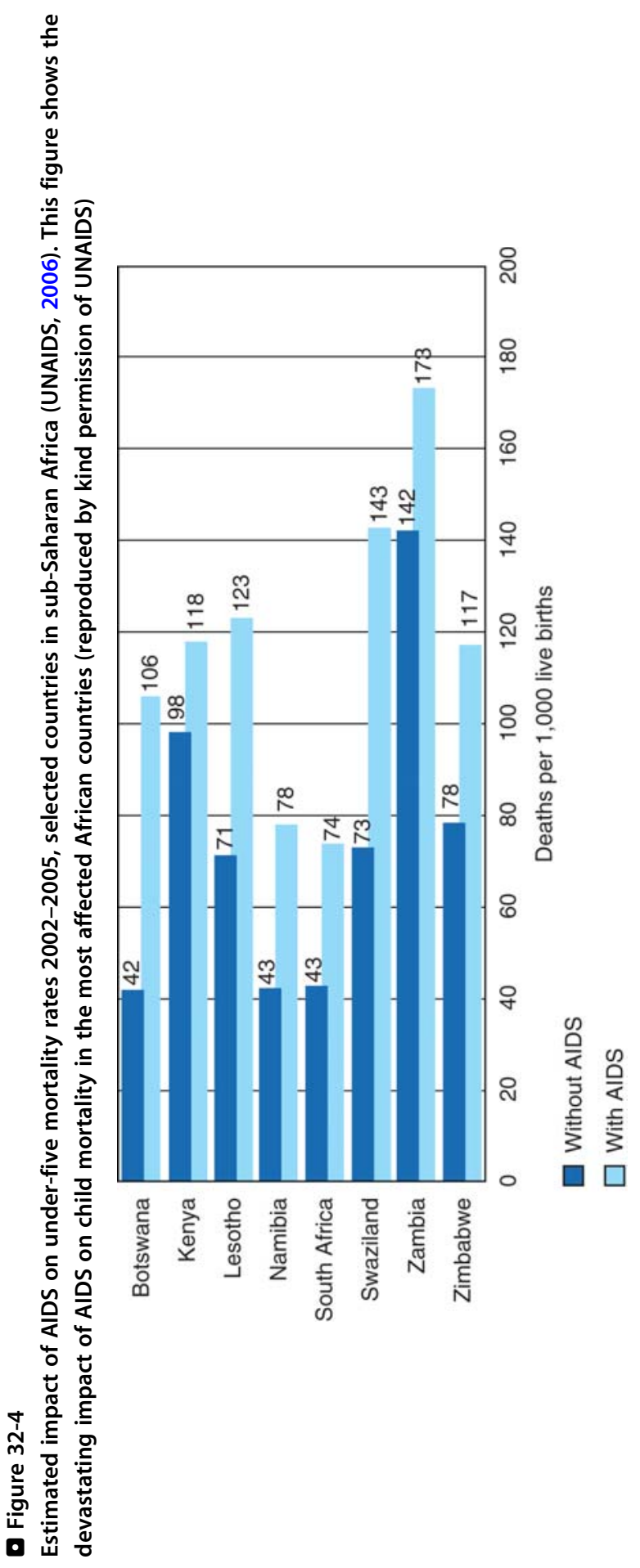


- Table 32-6

Disease burden due to diarrhea worldwide

\begin{tabular}{|l|l|l|}
\hline Authors & Deaths per year & $\begin{array}{l}\text { Period covered and data used in the } \\
\text { review }\end{array}$ \\
\hline Rohde and Northrup (1976) & 5 million & Author's data, 1976 \\
\hline Snyder and Merson (1982) & 4.6 million & $\begin{array}{l}\text { Review of data published between } \\
1954 \text { and 1979 }\end{array}$ \\
\hline NVD-US Institute of Medicine (1986) & 3.5 million & $\begin{array}{l}\text { Based on published data and field } \\
\text { experience }\end{array}$ \\
\hline Bern et al. (1992) & 3.3 million & $\begin{array}{l}\text { Using data published between } 1980 \\
\text { and 1990 }\end{array}$ \\
\hline Murray et al. (2001) & 1.4 million & Data analysis in 2000 \\
\hline Kosek et al. (2003) & 2.5 million & $\begin{array}{l}\text { Using data published between } 1992 \\
\text { and 2000 }\end{array}$ \\
\hline WHO (2003a) & 1.9 million & $\begin{array}{l}\text { Report: Global defence against the } \\
\text { infectious disease threat, data } 2001\end{array}$ \\
\hline
\end{tabular}

Various estimates provided by different authors who have tempted to evaluate the disease burden caused by diarrhea diseases. They all show a declining trend in mortality but morbidity remains relatively stable

\subsection{Malaria}

In developing countries, every year, malaria affects some 300 million people and kills more than a million of them. A large proportion of those who survive will end up with disability. The quasi-totality of people suffering from malaria lives in developing countries. It should be noted that the most exposed and vulnerable people are among children, pregnant women and those already weakened by other health and socio-economic conditions like malnutrition, pulmonary infections and lack of water and sanitation. Countries in tropical Africa bear the brunt of malaria, accounting for more than $90 \%$ of all cases occurring worldwide each year (Ruxin et al., 2005).

\subsection{Tuberculosis}

About $95 \%$ of deaths caused by tuberculosis (TB) take place in developing countries. Being among the top ten causes of global mortality, TB is the second leading cause of adult death due to infectious disease (Borgdorff et al., 2002; Dye, 1999; Laxminarayan et al., 2007). It has been estimated that approximately one-third of the world's population is infected with tuberculosis bacillus, and that each year nearly 9 million people develop tuberculosis disease and about 2 million die of it. South-East Asia and Africa are the most affected. It should be stressed that HIV/AIDS epidemic and multi-drug resistance have worsened the tuberculosis situation over the last two decades. Tuberculosis is a leading killer of people with HIV, and $80 \%$ of tuberculosis patients are HIV positive in countries with high prevalence of HIV (Dye, 1999; Ruxin et al., 2005). The most devastating impact of tuberculosis is death; without treatment, twothirds of smear-positive cases die within 5 years, with most dying within 18 months of being infected (Laxminarayan et al., 2007). 


\subsection{Preventable Sexually Transmitted Diseases}

In the era of AIDS and the high level of politicization and priority given to HIV, other sexual transmissible diseases may receive less attention. It is the case of preventable sexually transmitted diseases (STD) which caused in 1999, about 350 million infections in the population aged 15-49. However, knowing the correlation existing between STD and HIV/AIDS, health policy makers should be very careful. An illustrative example is given by the case of North African countries, known to have high prevalence of STD and, so far, relatively saved from high prevalence of HIV/AIDS but the increasing trend may explode rapidly (Boutayeb, 2006).

Congenital syphilis is still endemic in many African countries. An estimated 4 million cases occurred in 1999 among adults in sub-Sahara Africa, a similar number of cases was recorded in south and south-east Asia and 3 million cases took place in Latin America and the Caribbean (Berman, 2003; Hawkes et al., 2003; Peeling and Ye, 2003; Schmidt, 2003). It is worth stressing that all these cases are happening while tools of prevention have been available for decades.

\subsection{Respiratory Infections}

According to WHO estimates, Respiratory infectious diseases were the first cause of mortality from infectious diseases in 2001, responsible for nearly 4 million deaths principally in developing countries. In 2002, lower respiratory infections caused nearly 2 million deaths in children, ranking at the second leading cause.

\subsection{Neglected Diseases}

An exhaustive deal with all communicable diseases in developing countries is beyond the scope of this chapter. However, we cannot overlook the multitude of infectious diseases which are so-called "neglected diseases" due to the little consideration they have been given at national and international levels. Indeed, lymphatic filariasis, leishmaniasis, schistosomiasis, sleeping sickness, dengue, Chagas disease, Buruli ulcer and others are responsible for impaired childhood growth, mental retardation, blindness, amputation and diverse disability conditions almost exclusively in developing countries (Boutayeb, 2007; Derouich and Boutayeb, 2006; See details in the Chapter The burden of neglected diseases in developing countries of this book).

\section{Discussion and Conclusion}

In developing countries nearly 3 billion people live with less than 2 dollars a day, 1.2 billion live with one dollar a day, 1.3 billion live on fragile and often remote rural ecosystems, and about 2 billion people have inadequate or no access to life-saving treatments. On top of natural catastrophes, poverty, wars and conflicts, these countries are exposed to a double burden of communicable and noncommunicable diseases with alarming trends. Some diseases like tuberculosis are both causes and consequences of poverty. Other diseases like diabetes and cardio vascular diseases are more associated with different transition forms (demographic, economic, geographic and epidemiological) in which middle income countries are engaged. Globally, however, the double action of communicable and noncommunicable diseases constitute serious 
impediments to economic development by reducing productivity, setting aside saving possibilities and slowing economic growth in general. They also obstruct human development by their negative action on life expectancy, education and socio-economic status in general. The economic cost of care for noncommunicable diseases such as CVDs, diabetes, COPD and cancer is huge. The adequate treatment for communicable diseases like HIV/AIDS, tuberculosis and malaria is beyond the capacity of most developing countries. In the main time, diseases are causing the loss of billions of dollars in terms of non productivity, absenteeism and skill. The global disease impact has a special feature in developing countries since most of the diseases affect either children or adults in their most productive part of life. Consequently, life expectancy, education, income and all human development components are affected by communicable and/or noncommunicable in developing countries. The disease burden is a major problem for health public and a real global concern for the whole economic and human development (Malawi, 2005; South Africa, 2003; UNESCO, 2007; UNICEF, 2005; Zimbabwe, 2003).

\section{Summary Points}

- In developing countries, nearly $50 \%$ of the disease burden is caused by deaths under age 15 , compared to $10 \%$ in developed countries.

- The five biggest infectious killers in the world and in Africa are acute respiratory infections, HIV/AIDS, diarrhea, malaria and tuberculosis.

- Diabetes is a disorder in which the body becomes unable to control the amount of sugar in the blood.

- Type2 diabetes is the most frequent, representing $85-90 \%$ and characterized by a partial lack of insulin or its efficiency. It generally affects people aged 40 years and plus, generally treated with diet and tablets.

- Typel diabetes is characterized by a total lack of insulin due the destruction of beta cells producers of this vital hormone. This type of diabetes affects children and young adults, for this reason it is also called juvenile diabetes or insulin-dependent diabetes. It's treatment necessitate the daily injection of insulin.

- Hyperglycemia occurs when the blood sugar is higher then the usual threshold. It indicates the onset of diabetes and/or its bad control in known diabetic people.

- Hypoglycemia is the state where blood sugar is lower than the normal concentration which is around one gram per liter or $6 \mathrm{mmol}$.

- In 2007, about 300 billion US\$ (215-375) were spent worldwide in care for diabetes and its complications.

- Body Mass Index (BMI) is the ratio given in $\mathrm{kg} / \mathrm{m}^{2}$ and obtained by dividing the weight of a person by the square of its height. A person is said to be obese if its BMI is greater than $30 \mathrm{~kg} / \mathrm{m}^{2}$.

- Chronic obstructive pulmonary disease (COPD) causes 2.5 million deaths and some 25 million DALYs every year.

- An estimated 17.5 million deaths were caused by CVDs in 2005, representing 30\% of all deaths occurring in the world.

- In $2000,53 \%$ of the 10 million new cases and $56 \%$ of the 7 million deaths caused by cancer, occurred in developing countries.

- Directly Observed Therapy Strategy (DOTS) is the most efficient strategy so far to control tuberculosis and limit its burden. 


\section{References}

Abegunde DO, Mathers CD, Adam T, Ortegon M, Strong K. (2007). Lancet. 370: 1929-1932.

Ait-Khaled N, Enarson D, Bousquet J. (2001). Bull World Health Organ. 79: 971-979.

Alwan A. (1997). East Mediterr Health J. 3: 6-16.

Berman SM. (2003). Bull World Health Organ. 82: 433-438.

Bern C, Martines J, de Zoysa I, Glass RI. (1992). Bull World Health Organ. 70: 705-714.

Borgdorff MW, Floyd K, Broekmans JF. (2002). Bull World Health Organ. 80: 217-227.

Boutayeb A. (2006). Trans R Soc Trop Med Hyg. 100: 191-199.

Boutayeb A. (2007). Int J Equity Health. doi: 10.1186/ 1475-9276-6-20.

Boutayeb A, Boutayeb S. (2005). Int J Equity Health. doi: 10.1186/1475-9276-4-2.

Boutayeb A, Twizell EH, Achouyab K, Chetouani A. (2004). BioMed Eng. doi: 1186/1475-925X-3-20.

Buist AS, McBurine MA, Vollmer WM, BOLD group. (2007). Lancet. 370: 741-750.

Derouich M, Boutayeb A. (2006). Appl Math Comput. 177: 528-544.

Drewnowski A, Specter SE. (2004). Am J Clin Nutr. 79: 6-16.

Dye C (1999). Int J Tuberc Lung Disease. 4: 146-152.

Dzenovska D, Rasheed N, Sandkjaer B. (2005). HIV/ AIDS and Human Development Thematic Guidance Note. UNDP, New York, NY.

Ezzati M, Lopez AD. (2000). Lancet. 362: 847-852.

Hawkes S, Miller S, Rechenbach L, Nayyar A, Buse K. (2003). Bull World Health Organ. 82: 417-423.

Kosek M, Bern C, Guerrant RL. (2003). Bull World Health Organ. 81: 197-204.

Laxminarayan R, Klein E, Dye C, Floyd K, Dareley S, Adeyi O. (2007). Economic Benefit of Tuberculosis Control. The World Bank, Washington DC.

Lopez AD, Shibuya K, Rao C, Mathers CD, Ezzati M, Lopez AD. (2007). PLOS Negl Trop Dis. doi: 10.1371/journal.pntd.0000114.

Malawi HDR. (2005). Reversing HIV/AIDS in Malawi. United Nations Development Programme, Washington, DC.

Menezes AMB, Perez-Padilla R, Jardim JRB, PLATINO team. (2005). Lancet. 366: 1875-1881.

Moussavi S, Chatterji S, Verdes E, Tandon A, Patel V, Ustun B. (2007). Lancet. 307: 851-858.

Murray CJL, Lopez AD, Mathers CD, Stein C. (2001). The Global Burden of Disease 2002 Project. Word Health Organization, Geneva.

NVD. (1986). Establishing Priorities Volume 2. Institute of Medicine, Washington, DC.
Peeling RW, Ye H. (2003). Bull World Health Organ. 82: $439-446$.

Reddy K. (2002). Public Health Nutr. 5: 231-237.

Rohde JR, Northrup RS. (1976). In: Ciba Foundation Symposium (ed.) Acute Diarrhoea in Children. Elsevier, Amsterdam, pp. 339-365.

Ruxin J, Paluzzi JE, Wilson PA, Tozan Y, Kruk M, Teklehaimanot A. (2005). Lancet. 365: 618-621.

Schmidt G. (2003). Bull World Health Organ. 82: 402-409.

Snyder JD, Merson MH. (1982). Bull World Health Organ. 60: 605-613.

South Africa. (2003). Human Development Report. http://www.undp.org.za Cited 8 Dec 2007.

Tazi M, Abirkhalil S, Chaouki N, Cherkaoui S, Lahmouz F, Srairi J, Mahjour J. (2003). J Hypertens. 21: 897-903.

The Lancet. (2007). The Lancet. 370: 713-713.

Thornicroft G. (2007). Lancet. 370: 807-808.

UNAIDS. (2006). The Impact of AIDS on People and Societies. http://data.unaids.org Cited 20 Dec 2007.

UNESCO. (2007). Education for All in Least Developed Countries. http://unesdoc.unesco.org Cited $20 \mathrm{Dec}$ 2007.

UNICEF. (2005). The State of the World's Children. The United Nations Children's Fund, New York.

WHO. (2002). World Health Organization Annual Report. http://www.who.int/whr/2002/en Cited 20 Dec 2007.

WHO. (2003a). Global Defence Against the Infectious Diseases Threat. World Health Organization, Geneva.

WHO. (2003b). World Health Organization annual Report. http://www.who.int/whr/2003/en Cited 20 Dec 2007.

WHO. (2003c). Diet, Nutrition and the Prevention of Chronic Diseases. World Health Organisation, Geneva.

WHO. (2004). World Health Organization Annual Report. http://www.who.int/whr/2004/en Cited 20 Dec 2007.

WHO. (2007). World Health Organization Annual Report. http://www.who.int/whr/2007/en. Cited 20 Dec 2007.

Yin P, Jiang CQ, Cheng KK, Lam TH, Miller MR, Zhang WS, Thomas GN, Adab P. (2007). Lancet. 370: 751-757.

Yusuf S, Reddy KS, Ounpus S, Anand S. (2001). Circulation. 104: 2746-2753.

Zimbabwe HDR. (2003). Redirecting our Responses to HIV and AIDS. United Nations Development Programme, Washington, DC. 